\title{
TWO SEX-LINKAGES IN THE HOUSE MOUSE, WITH UNUSUAL RECOMBINATION VALUES
}

\author{
MARGARET E. WRIGHT \\ (Mrs M. E. WALLACE) \\ Deportment of Genetics, University of Combridge
}

Received 5.vi.47

IN 1945, in Line Thirteen of the series of inbred lines set up by Professor R. A. Fisher in the house mouse, Mus musculus, a disturbed segregation of shaker $\left(s h_{2}\right)$ and sex was noticed. Data collected from three unrelated lines, Eight, Twelve and Eighteen, in which wavy $\left(w v_{2}\right)$ and shaker $\left(s h_{2}\right)$ were segregating, indicated linkage between these two factors and sex. G. D. Snell and L. W. Law (I939) had published data from which a crossover value of 25 per cent. between wavy and shaker had been obtained. An experiment was therefore set up, designed to investigate their linkage relations not only with each other but also with sex.

Appropriate genotypes were taken from Lines Twelve and Eighteen and a separate stock of wavy and shaker; crosses were made to produce each of the four kinds of males needed.

$$
\begin{aligned}
& \text { (i) Tricoupling } \\
& \frac{w w v_{2} s h_{2} \mathrm{X}}{+\quad+\mathrm{Y}} \\
& \text { (ii) } w v_{2} \text { and } s h_{2} \text { in coupling } \frac{\delta w v_{2} s h_{2} \mathrm{Y}}{++\mathrm{X}} \\
& \text { (iii) } s h_{2} \text { and sex in coupling } \frac{\widehat{\sigma}+s h_{2} \mathrm{X}}{w v_{2}+\mathrm{Y}} \\
& \text { (iv) } w v_{2} \text { and sex in coupling } \frac{\tau}{t} \frac{w v_{2}+\mathrm{X}}{+s h_{2} \mathrm{Y}}
\end{aligned}
$$

In order that any causes other than linkage, likely to disturb the ratios obtained, should be distributed at random throughout the matings, mates were chosen during the following generations without regard to their consanguinity. Approximately a hundred mice were bred from each type of triple backcross (comprising twenty-four matings). The results are tabulated by phenotypes on page $35^{\circ}$ (table I).

In a form more convenient for considering linkage relations, these data may be tabulated as under, the columns representing respectively :

I. Parental types.

II. Recombinants, with crossovers interchanging $\mathrm{X}$ and $\mathrm{Y}$. 


\begin{tabular}{|c|c|c|c|c|c|c|c|}
\hline \multirow{11}{*}{ 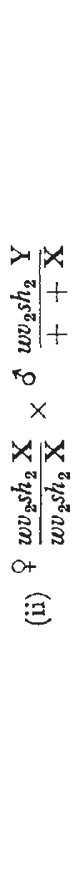 } & 莒 & 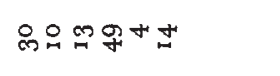 & $\stackrel{\circ}{\sim}$ & \multirow{11}{*}{ 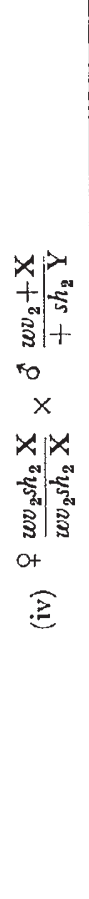 } & 胥 & लैవి స్ & 8 \\
\hline & + & treserar a & 0 & & + & $\mathrm{N} \mathrm{cmm}$ & s \\
\hline & है & $\alpha$ a d con & $=$ & & कू & OHNa & สิ \\
\hline & 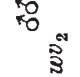 & & $\omega$ & & 每 & $\infty \operatorname{nn}$ & สิ \\
\hline & 离 & ontri: & 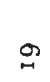 & & ज్ & HWm & $\infty$ \\
\hline & & & & & & & \\
\hline & + & ณn- & $=$ & & + & $\vdots-+\alpha$ & r \\
\hline & $\frac{0+}{25}$ & & $\omega$ & & ot & N & $\stackrel{\infty}{\sim}$ \\
\hline & న్ & a $\vdots m m m$ & 6 & & కี & a d a m & n \\
\hline & 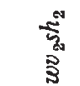 & $\infty-\alpha m \vdots n$ & aे & & 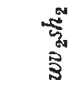 & $\operatorname{man} n$ & os \\
\hline & 藍 & 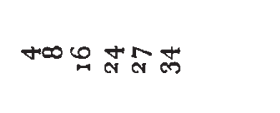 & $\vdots$ & & 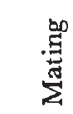 & 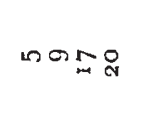 & $\vdots$ \\
\hline \multirow{10}{*}{ 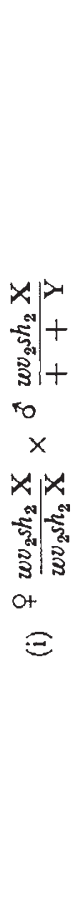 } & $\bar{\Xi}$ & வாの+ニ & $\stackrel{0}{0}$ & \multirow{10}{*}{ 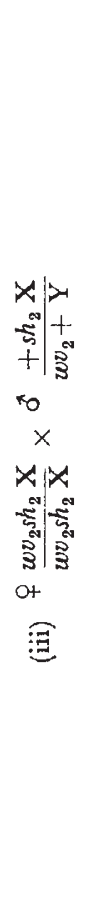 } & $\overline{0}$ & $\bar{\pi} \tilde{n}_{\infty}^{\infty} \infty$ & s \\
\hline & + & $-\vdots \vdots \vdots+\infty-\vdots-$ & 운 & & + & $\vdots+\infty \vdots \infty$ & $a$ \\
\hline & 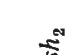 & 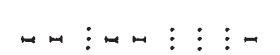 & in & & รี & toog $\mathrm{H}$ & के \\
\hline & 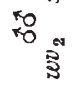 & $\vdots \vdots \propto \vdots \vdots \pi-$ ๙ & 움 & & 知 & $\ln \ln x$ & \& \\
\hline & క్ & 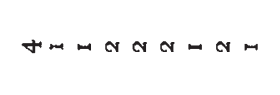 & $\infty$ & & $\begin{array}{l}\text { స్ } \\
\text { స్ } \\
\text { న్ }\end{array}$ & $\vdots$ Nen $\vdots-$ & $z$ \\
\hline & + & 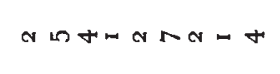 & $\stackrel{\infty}{\sim}$ & & + & $\min m \vdots-$ & $\cong$ \\
\hline & है & 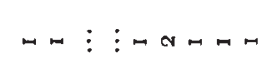 & $\infty$ & & हा & twone & $\stackrel{\circ}{\pi}$ \\
\hline & O+ & $\operatorname{man} a \vdots$ a & $\mathscr{R}$ & & के & tone $\cos$ & สี \\
\hline & 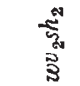 & $m a \vdots-\alpha-\alpha$ ar & $m$ & & 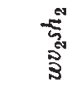 & $+\infty n-m$ & $\circ$ \\
\hline & 晜 & MN=Nম & $\vdots$ & & 占 & $\omega m \tilde{\sim} \approx$ ก & $\vdots$ \\
\hline
\end{tabular}


III. Recombinants, with crossovers interchanging $w v_{2}$ and its normal allelomorph.

IV. Recombinants, with crossovers interchanging $s h_{2}$ and its normal allelomorph.

TABLE 2

Observed $(\mathrm{m}+\mathbf{x})$

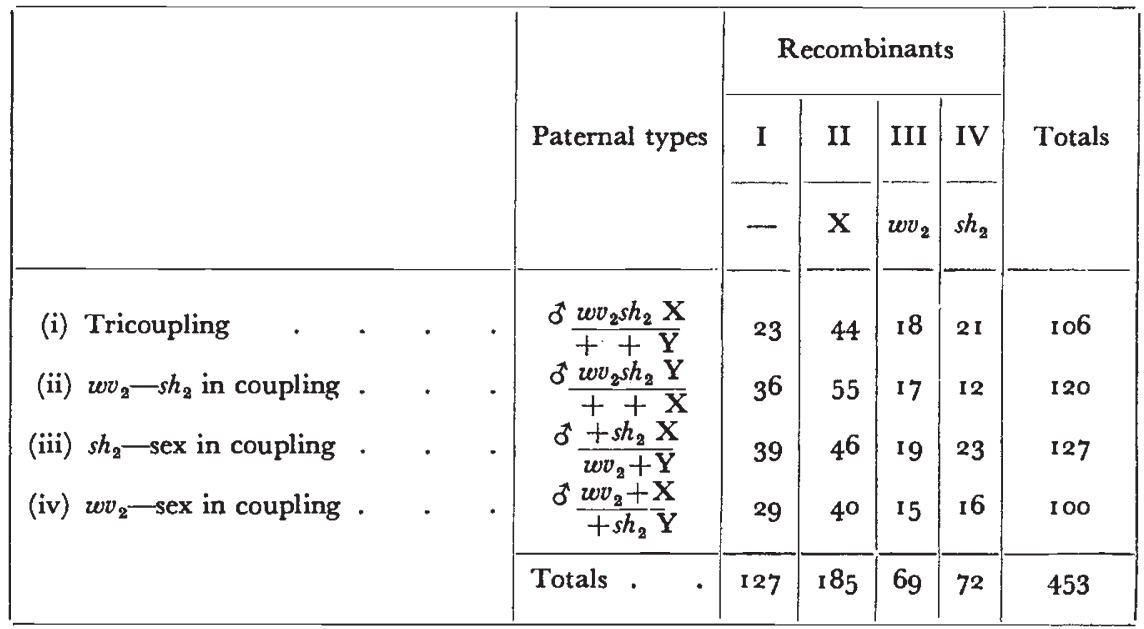

It will be seen that this table involves the grouping of data concerning pairs of complementary genotypes from each kind of mating, these pairs being arranged as are the letters in a symmetrical $4 \times 4$ Latin Square. If there are any viability differences they may normally be expected to show most plainly between the members of these pairs. A $\chi^{2}$ test on their approximation to $\mathrm{I}: \mathrm{I}$ ratios will indicate if any of these pairs of genotypes are unequally viable (table 3).

TABLE 3

\begin{tabular}{|c|c|c|}
\hline $\begin{array}{l}\text { Pairs of complementary } \\
\text { genotypes }\end{array}$ & Totals & $x^{2}$ \\
\hline 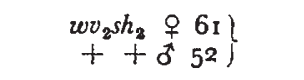 & I13 & 0.7168 \\
\hline $\left.\begin{array}{rrr}++ & + & 64 \\
w v_{2} s h_{2} & \sigma^{*} & 54\end{array}\right\}$ & I 18 & 0.8475 \\
\hline $\left.\begin{array}{r}+s h_{2}+{ }_{1} \\
w w v_{2}+d^{1} \\
58\end{array}\right\}$ & 109 & 0.4495 \\
\hline \multirow[t]{2}{*}{ 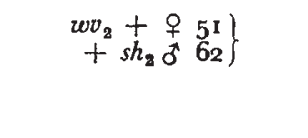 } & I 13 & I $\cdot 0708$ \\
\hline & 453 & $3 \cdot 0846 ; n=4$ \\
\hline
\end{tabular}

The low $\chi^{2}$ indicates that there are no obvious viability disturbances. 
A further and more comprehensive test, to discern whether viability or any other factors are disturbing the data, may be made by comparing the observed frequencies with those expected on the basis of the marginal totals in table 2 (table 4 ) :

TABLE 4

(a) Expected (m)

\begin{tabular}{|c|c|c|c|c|c|}
\hline & I & II & III & IV & \\
\hline (i) & $29 \cdot 7174$ & $43 \cdot 2892$ & $16 \cdot 1457$ & $16 \cdot 8477$ & $106 \cdot 0000$ \\
(ii) & $33 \cdot 6424$ & $49 \cdot 0066$ & $18 \cdot 2781$ & $19 \cdot 0729$ & $120 \cdot 0000$ \\
(iii) & $35 \cdot 6049$ & $51 \cdot 8653$ & $19 \cdot 3444$ & $20 \cdot 1854$ & $127 \cdot 0000$ \\
(iv) & $28 \cdot 0353$ & $40 \cdot 8389$ & $15 \cdot 2318$ & $15 \cdot 8940$ & $100 \cdot 0000$ \\
\cline { 2 - 5 } & $127 \cdot 0000$ & $185 \cdot 0000$ & $69 \cdot 0000$ & $72 \cdot 0000$ & $453 \cdot 0000$ \\
\hline
\end{tabular}

(b) $\left(\mathrm{x}^{2} / \mathrm{m}\right)$

\begin{tabular}{|c|c|c|c|c|c|}
\hline & I & II & III & IV & Total $\chi^{2}$ \\
\hline \multirow{2}{*}{ (i) } & I.5184 & 0.0117 & 0.2130 & 1.0234 & \\
(ii) & 0.1652 & 0.7330 & 0.0894 & 2.6229 & \\
(iii) & 0.3237 & 0.6633 & 0.0061 & 0.3925 & \\
(iv) & 0.0332 & 0.0172 & 0.0035 & 0.0071 & \\
\cline { 2 - 5 } & 2.0405 & 1.4252 & 0.3120 & 4.0459 & $7.8236(n=9)$ \\
\hline
\end{tabular}

The $\chi^{2}$ is again insignificant for these nine degrees of freedom.

Finally, any inequality due to viability or other factors between the four pairs of genotypes in table 3, which might have disturbed the linkage relations, will become evident by comparison with the expected frequencies of these genotypes; these can be drawn from table $4 a$ and appear below, together with a $\chi^{2}$ test comparing them (table 5) :

TABLE 5

\begin{tabular}{|c|c|c|c|}
\hline Genotypes & Expected (m) & Observed $(m+x)$ & $x^{2} / m$ \\
\hline \multirow[t]{2}{*}{ 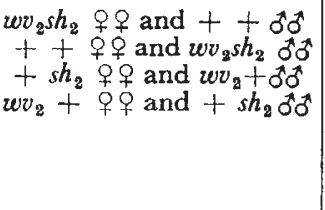 } & $\begin{array}{l}x 13 \cdot 9624 \\
112 \cdot 3488 \\
111.6624 \\
115.0264\end{array}$ & $\begin{array}{l}113 \\
118 \\
109 \\
113\end{array}$ & $\begin{array}{l}0.00813 \\
0.28426 \\
0.06348 \\
0.03570\end{array}$ \\
\hline & $453 \cdot 0000$ & 453 & $\begin{array}{c}0.39157 \\
(n=3)\end{array}$ \\
\hline
\end{tabular}

The $\chi^{2}$ is extremely low, and contributes very little to the total $\chi^{2}$ of $7 \cdot 823^{6}$ for nine degrees of freedom (in table $4 b$ ).

It appears, therefore, that viability and other disturbances are negligible. 
It remains to test the hypothesis of independent segregation of sex with shaker and wavy. A $\chi^{2}$ test on the approximation to a I : I ratio of the parental types of offspring against the recombinants involving an interchange of $X$ and $Y$ is given below :

\begin{tabular}{|c|c|c|c|}
\hline Parental types & Recombinants & $\chi^{2}$ & \\
\hline 127 & 185 & $10 \cdot 782$ & $(n=1)$ \\
\hline
\end{tabular}

The value of $\chi^{2}$ for one degree of freedom is equivalent to a normal deviate of 3.284 standard deviation; the one in Iooo level of significance requires $3 \cdot 24 \mathrm{I}$. The hypothesis of independence is therefore untenable.

It is reasonable, therefore, to conclude that the factors wavy and shaker are linked, not only with each other, but also with sex. The recombination values derived from table 2 are (table 6 ) :

TABLE 6

\begin{tabular}{|c|c|c|c|c|c|c|}
\hline Linked loci & Recombinants & Total & \multicolumn{2}{|c|}{$\begin{array}{l}\text { Percentage } \\
\text { recombination }\end{array}$} & \multicolumn{2}{|c|}{$\begin{array}{l}\text { Standard } \\
\text { error }\end{array}$} \\
\hline$w v_{2}$ and $s h_{2}$ & $69+72=141$ & 453 & $3^{1 \cdot 06}$ & r cent. & \multicolumn{2}{|c|}{$2 \cdot 174$ per cent. } \\
\hline$w v_{2}$ and sex & $185+69=254$ & 453 & $56 \cdot 07$ & ", & $2 \cdot 33^{2}$ & , \\
\hline$s h_{2}$ and sex & $185+72=257$ & 453 & $56 \cdot 73$ & ", & $2 \cdot 328$ & ", \\
\hline
\end{tabular}

The recombination value between shaker and wavy is higher than that found by Snell and Law (1939). However, their estimate was based principally on female gametogenesis, and that given above is based on male gametogenesis ; it is not impossible, therefore, that they should differ. For males, Snell and Law report 15 recombinants out of 56 , an observation not incompatible with a recombination value exceeding 30 per cent.

The two main conclusions to be drawn from table 6 are : first, that the recombination values between shaker and sex and between wavy and sex are both significantly greater than 50 per cent. ; and, secondly, that the two loci, wavy and shaker, recombination between which is as great as $3^{1}$ per cent., are nevertheless similarly related as regards their values with sex.

Explanation of these phenomena is outside the scope of this paper, but it is submitted that while these conclusions appear mutually repugnant, the data given above supply very strong evidence for each of them. 
I am indebted to Professor R. A. Fisher for his guidance and encouragement and for the use of his stocks ; and also to Mr T. C. Carter and Miss M. F. I. Speyer for their help in completing the experiment.

\section{REFERENCE}

SNELL, G. D., and LAW, L. W. I 939 .

A linkage between $s h_{2}$ and $w v_{2}$ in the house mouse.

7. Hered. 30,447 . 